\title{
Characterization and Dehydration Behavior of a Natural, Ammonium Hydroxide, and Thermally Treated Zeolitic Tuff
}

\author{
G. Narin, D. Balköse, and S. Ülkü \\ Department of Chemical Engineering, Izmir Institute of Technology, Izmir, Turkey
}

\begin{abstract}
Aqueous $\mathrm{NH}_{4} \mathrm{OH}$-treated and subsequently calcined forms of local natural zeolitic tuff were characterized by different techniques including scanning electron microscopy (SEM), X-ray powder diffraction, inductively coupled plasma-atomic emission spectroscopy (ICP-AES), volumetric $\mathrm{N}_{2}$ adsorption at $-196^{\circ} \mathrm{C}$, thermogravimetry (TG), differential scanning calorimetry (DSC), and transmittance infrared spectroscopy. The dehydration behavior of the samples was investigated using an in situ temperature-programmed diffuse reflectance Fourier transform infrared spectroscopy (TP-DRIFTS) method under vacuum. The DRIFTS spectra recorded yielded information about the effect of the $\mathrm{NH}_{4} \mathrm{OH}$ treatment and subsequent calcination on the dehydration behavior of the natural zeolite. Changes in the infrared bands corresponding to vibrations of the $\mathrm{O}-\mathrm{H}$ and $\mathrm{N}-\mathrm{H}$ bonds upon in situ heating under vacuum were analyzed.
\end{abstract}

Keywords Ammonium hydroxide treatment; Characterization; Clinoptilolite; Dehydration; DRIFTS

\section{INTRODUCTION}

Natural zeolites constitute a group of minerals having open aluminosilicate frameworks containing channels and cavities that accommodate cations and water molecules. Generally, these cations are exchangeable and the water molecules can be removed or replaced reversibly without disrupting the framework. The presence of water in the pores hinders adsorption of other molecules; thus adsorption and catalytic properties of zeolites are directly related to their water content. Water is adsorbed into zeolites by filling oxygen-lined channels and hydrating the cations present in the channels. The observed macroscopic thermal behavior of a zeolite depends on the type, amount, and position of the extraframework cations within the structure, their coordination to water molecules, their interactions with framework oxygen atoms, the presence of other water molecules, $\mathrm{Si} / \mathrm{Al}$ ratio, time, temperature, pressure, and heating rate.

Dehydration behaviors of clinoptilolite have been investigated by various analytical techniques including

Correspondence: G. Narin, Department of Chemical Engineering, Usak University, 64200 Usak, Turkey; E-mail: guler. narin@usak.edu.tr thermogravimetry (TG), differential thermogravimetry (DTG), differential thermal analysis (DTA), differential scanning calorimetry (DSC), ${ }^{[1-8]}$ infrared spectroscopy, ${ }^{[9]}$ and single-crystal X-ray diffraction, ${ }^{[10]}$ and different types of water were identified in clinoptilolite.

Van Reenwiijk reported three endothermic DTA peaks for clinoptilolite. Based on the entropy values of water in the zeolite calculated from the DSC curves, at least three types of water were identified in the zeolite, including crystal water or low-entropy water, loosely bound water with high entropy, and zeolitic or high-entropy water. ${ }^{[8]}$ Thermal and vacuum dehydration analysis of clinoptilolite-rich tuffs by DSC revealed the presence of three types of water as externally adsorbed, loosely bound zeolite, and tightly bound zeolite water and the heats of dehydration of each type of water were calculated as 54.4-65.8, 52.3-64.5, and $76.2-160 \mathrm{~kJ} / \mathrm{mol} \mathrm{H}_{2} \mathrm{O}$, respectively. ${ }^{[2]}$

Adsorption and desorption of water vapor on zeolites are reversible, i.e., the amount of heat required for desorption is equal to that released during adsorption. The application of zeolite for water adsorption is widely investigated for many purposes. Clinoptilolite and its $\mathrm{Na}, \mathrm{K}, \mathrm{Ca}, \mathrm{H}$, and $\mathrm{NH}_{4}$ forms were tested for their applications in drying of air, hydrocarbons, $\mathrm{H}_{2}$, etc. ${ }^{[4,11-13]}$ Adsorption drying with zeolite was proposed as an alternative method to improve the energy efficiency of industrial drying. ${ }^{[14-18]}$ The principle of zeolite drying is based on dehumidification of air before feeding to the dryer. At the same time, the air is preheated due to the release of adsorption heat, and the driving force for drying is increased. Zeolite 13X exhibited higher water adsorption capacity and better heat and mass transfer properties than pillared clays (PILCS), natural clay, and sand in immersion drying of wheat in an agitated particulate medium dryer. ${ }^{[14]}$ It was shown that dryers using a zeolite air dehumidifier were more energy efficient than conventional dryers operating at moderate temperatures $\left(52-70^{\circ} \mathrm{C}\right)$ in the food industry. ${ }^{[15]}$ Zeolite was found to be more favorable than alumina-pillared clay for low drying temperatures $\left(40-50^{\circ} \mathrm{C}\right)$ in multistage adsorption dryers with air dehumidification. ${ }^{[18]}$ The two-stage dryer using zeolite for air dehumidification was found to be more 
energy efficient than the one-stage system and current drying systems. ${ }^{[17]}$ Local natural zeolite was proposed as a cheap substitute for expensive synthetic adsorbents also for industrial air drying applications. ${ }^{[19]}$ Hydration and dehydration behaviors of local natural zeolites were investigated for drying and energy storage applications. ${ }^{[19-26]}$ In such drying systems, the initial water content of the zeolite is important because it determines the adsorption capacity of the zeolite for water vapor. Based on the results of water vapor adsorption studies performed on an adsorbent bed, the local zeolite used in corn drying led to a significant increase in the drying rate and in the total amount of water desorbed for the same drying period. Furthermore, the heat released by the zeolite as it adsorbed water $(100,000$ $2,500 \mathrm{~J} / \mathrm{g}$ in the range of $0.01-0.115 \mathrm{~g} \mathrm{H}_{2} \mathrm{O} / \mathrm{g}$ zeolite) was found to be higher than that absorbed by the corn during drying. ${ }^{[20]}$ Heat of adsorption of water vapor in clinoptilolite-rich tuffs decreased from -64.1 to $-47.7 \mathrm{~kJ} / \mathrm{mol} \mathrm{H}_{2} \mathrm{O}$ as the solid moisture content increased from 4 to $11.5 \%$ $(\mathrm{w} / \mathrm{w}){ }^{\left[{ }^{[24]}\right.}$ The monolayer water vapor adsorption capacity was $9.68 \mathrm{~g} \mathrm{H}_{2} \mathrm{O} / \mathrm{g}$ zeolite and the heat of adsorption values were reported as -65.4 and $-32.7 \mathrm{~kJ} / \mathrm{mol} \mathrm{H}_{2} \mathrm{O}$ for 1 and $5 \%(\mathrm{w} / \mathrm{w})$ solid moisture contents, respectively. ${ }^{[26]}$ Recently, Alver et al. ${ }^{[27]}$ correlated the thermal behavior of clinoptilolite-rich natural zeolites from Turkey and their cation-exchanged forms to the size, particularly to the hydration energy, of the nonframework cations. The dehydration enthalpy change values were measured in the range of $9.84-14.60 \mathrm{~kJ} / \mathrm{mol} \mathrm{H}_{2} \mathrm{O}$ by DSC. ${ }^{[27]}$

The thermal analysis techniques do not provide information about the state of the water molecules during dehydration of the zeolite. Infrared spectroscopic techniques are one of the methods that can be employed for this purpose. ${ }^{[9,28]}$ Breger et al. distinguished between different types of water retained in clinoptilolite based on the infrared measurements and used the terms loosely held and tightly bound water to describe the types of water based on the intensities of 3410 and $3610 \mathrm{~cm}^{-1}$ bands, respectively. ${ }^{[9]}$

Temperature-programmed diffuse reflectance Fourier transform spectroscopy (TP-DRIFTS) allows analysis of the dehydration behavior of zeolites under similar conditions as in the thermal analysis methods. Beta et al. studied nonisothermal desorption of water on alkali-metal cation-exchanged X-type zeolites using TP-DRIFTS. ${ }^{[29]}$

In most adsorption and catalysis applications, $\mathrm{H}$ forms of zeolites are used. The $\mathrm{H}$ forms of zeolites are often prepared by thermal decomposition of their $\mathrm{NH}_{4}^{+}$forms. Kasture et al. showed that it was not possible to remove the ammonia from the $\mathrm{NH}_{4}$-exchanged clinoptilolite by heating at $250^{\circ} \mathrm{C}$ and to transform the $\mathrm{NH}_{4}$-clinoptilolite to the $\mathrm{H}$ form. ${ }^{[11]} \mathrm{In}$ infrared spectra of hydrated $\mathrm{NH}_{4}$ exchanged zeolites, the changes observed in the $\mathrm{OH}$ stretching vibrations were attributed to the presence of the $\mathrm{NH}_{4}$ groups and hydrogen bonds between the $\mathrm{NH}_{4}^{+}$ and $\mathrm{H}_{2} \mathrm{O}$. The desorption profiles were obtained from the change in the area of the $\mathrm{OH}$ stretching band with temperature. ${ }^{[30]}$ The mechanism of deammoniation consisted of thermal dissociation of $\mathrm{NH}_{4}^{+}$to $\mathrm{NH}_{3}$ and a proton and diffusion of $\mathrm{NH}_{3}$ out of the structure. ${ }^{[31]}$

Adsorption of gaseous ammonia has been employed in determination of acidity of zeolites. Adsorbed ammonia is coordinated on Brönsted acid sites ( $\mathrm{Si}-\mathrm{OH}-\mathrm{Al})$ in the protonated form of the zeolite (as $\mathrm{NH}_{4}^{+}$species; $1450 \mathrm{~cm}^{-1}$ ) or coordinated as $\mathrm{NH}_{3}$ species on the Lewis acid sites $\left(1625 \mathrm{~cm}^{-1}\right)$. The latter band overlaps with bands of physisorbed water. Individual $\mathrm{NH}_{4}^{+}\left(\mathrm{NH}_{3}\right)$ sites in a zeolite show different vibrational activities due to their different local group symmetries. Diverse coordinations of $\mathrm{NH}_{4}^{+}$ (monodendate, bidentate, tridentate) have been observed by infrared spectroscopy in a variety of zeolites. ${ }^{[32]}$

The aqueous ammonia solutions would also give information about the acidity of the zeolites. Thus, in this study, the effects of aqueous solutions of ammonia on a local clinoptilolite-rich zeolitic tuff are investigated. Natural, $\mathrm{NH}_{4} \mathrm{OH}$-treated, and subsequently calcined forms of the zeolitic tuff were characterized for this purpose. Moreover, dehydration behavior of a natural zeolite was investigated by TP-DRIFTS under vacuum for the first time. From the changes in the intensities of $\mathrm{O}-\mathrm{H}$ and $\mathrm{N}-\mathrm{H}$ bands upon heating under vacuum, the effects of the $\mathrm{NH}_{4} \mathrm{OH}$ treatment and subsequent calcination on the dehydration behavior of the zeolite were examined.

\section{MATERIALS AND METHODS \\ Preparation of Zeolite Samples}

Clinoptilolite-rich natural zeolitic tuff mined from Gördes (Western Anatolia, Turkey) was crushed, washed with hot deionized water, fractionated by wet sieving using Retsch Test Sieves, and the fraction with particle diameter range of 38-45 $\mu \mathrm{m}$ was used in the experiments after drying at $110^{\circ} \mathrm{C}$ overnight in a static oven. This sample was labeled as NZ. Twenty-five grams of NZ was treated with $250 \mathrm{~cm}^{3}$ of $2 \mathrm{~mol} / \mathrm{dm}^{3}$ aqueous ammonia solution, prepared from $\mathrm{NH}_{4} \mathrm{OH}$ (Sigma-Aldrich 221228, ACS reagent, Germany), at $75^{\circ} \mathrm{C}$ for 5,15 , and $45 \mathrm{~h}$ on a magnetic stirrer $(150 \mathrm{rpm})$. After the $\mathrm{NH}_{4} \mathrm{OH}$ treatment, the particles were washed with excess deionized water and dried at $110^{\circ} \mathrm{C}$ overnight. These samples were labeled as $\mathrm{NH}_{4}-\mathrm{NZ}-5 \mathrm{~h}, \mathrm{NH}_{4}-\mathrm{NZ}-15 \mathrm{~h}$, and $\mathrm{NH}_{4}-\mathrm{NZ}-45 \mathrm{~h}$, respectively. $\mathrm{NH}_{4}-\mathrm{NZ}-15 \mathrm{~h}$ was heated to $500^{\circ} \mathrm{C}$ in a static oven for $5 \mathrm{~h}$ and cooled to room temperature. The heating and cooling rates were $2^{\circ} \mathrm{C} / \mathrm{min}$. The sample obtained in this manner was labeled as $\mathrm{H}-\mathrm{NZ}$.

\section{Characterization}

\section{Scanning Electron Microscopy}

Particle and surface morphologies and crystal size and structures of the prepared samples were investigated by a 
scanning electron microscope (SEM, XL-30S FEG, Philips, Eindhoven, The Netherlands). The particles were mounted directly on a carbon tape before analysis.

\section{$X$-ray Powder Diffraction}

The crystal mineral composition of $\mathrm{NZ}$ was determined by the qualitative $\mathrm{X}$-ray powder diffraction analysis (XRD). The powder X-ray diffraction patterns of NZ, $\mathrm{NH}_{4}-\mathrm{NZ}-15 \mathrm{~h}$, and $\mathrm{H}-\mathrm{NZ}$ were recorded by a powder diffractometer (X'Pert Pro, Philips) equipped with an Ni-filtered $\mathrm{CuK}_{\alpha}$ radiation source $(\lambda=0.154056 \mathrm{~nm})$ over a $2 \theta$ range of $5^{\circ}$ to $40^{\circ}$ at a $10.15 \mathrm{~s}$ measurement time per step and a step size of $0.01671^{\circ}$. The X-ray source was operated at $40 \mathrm{~mA}$ and $45 \mathrm{kV}$. The sample preparation for the X-ray analysis involved gentle grinding of the particles into a fine powder using an agate mortar and pestle and packing of the powder into an aluminum sample holder with light compression to make it flat and tight.

\section{Chemical Composition Analysis}

The elemental compositions of NZ, $\mathrm{NH}_{4}-\mathrm{NZ}-15 \mathrm{~h}$, and $\mathrm{H}-\mathrm{NZ}$ were determined by an inductively coupled plasmaatomic emission spectrometer with axial plasma (ICP-AES; Liberty Series II, Varian, Victoria, Australia). The samples were treated with an alkali borate fusion flux (anhydrous lithium tetraborate, Fluka, Germany; zeolite in $10 \% \mathrm{w} / \mathrm{w}$ ) and dissolved in $1.6 \mathrm{~mol} / \mathrm{dm}^{3} \mathrm{HNO}_{3}$ prior to analysis.

The elemental compositions were also analyzed via energy-dispersive X-ray spectroscopy (EDS) combined with the SEM. The zeolite powders were pelletized by pressing under $200 \mathrm{kPa}$ pressure prior to the analyses. The EDS analyses were carried out on six randomly chosen regions on the surface of the pellets. The energy of the beam was $15 \mathrm{kV}$.

The carbon, hydrogen, and nitrogen contents of NZ and its $\mathrm{NH}_{4} \mathrm{OH}$ treated and successively calcined forms (H-NZ) were determined by elemental analysis (Leco 932 CHNS, Leco Corporation, St. Joseph, MI).

\section{Specific Surface Area and Pore Size}

The pore volumes and surface areas of the samples were measured by volumetric $\mathrm{N}_{2}$ adsorption-desorption at $-196^{\circ} \mathrm{C}$ using an ASAP 2010 (Micromeritics Instrument Corp., Norcross, GA). Prior to the analyses, the samples were degassed in situ at $300^{\circ} \mathrm{C}$ for $24 \mathrm{~h}$ under $5 \times$ $10^{-4}$ mbar.

\section{Thermogravimetric Analysis}

The changes in the mass of $\mathrm{NZ}, \mathrm{NH}_{4}-\mathrm{NZ}-15 \mathrm{~h}$ and $\mathrm{H}-\mathrm{NZ}$ upon heating were determined gravimetrically on a thermal gravimetric analyzer (TGA-51, Shimadzu, Kyoto, Japan) in the temperature range of $25-1000^{\circ} \mathrm{C}$. The analyses were performed using approximately $10 \mathrm{mg}$ samples, at a heating rate of $10^{\circ} \mathrm{C} / \mathrm{min}$ and under $40 \mathrm{~cm}^{3} / \mathrm{min}$ nitrogen flow. Prior to the analyses, the samples were hydrated on a saturated $\mathrm{NH}_{4} \mathrm{Cl}$ solution having $75 \%$ relative humidity at $25^{\circ} \mathrm{C}$ in a desiccator for 2 weeks.

\section{Differential Scanning Calorimetry}

Differential scanning calorimetry was carried out by a Shimadzu differential scanning calorimeter (DSC-50, Shimadzu) in temperature range of $20-600^{\circ} \mathrm{C}$ under $40 \mathrm{~cm}^{3} / \mathrm{min}$ nitrogen flow with a heating rate of $10^{\circ} \mathrm{C} /$ min. About $3.5 \mathrm{mg}$ zeolite was used in the DSC analysis. The heat of adsorption values for the samples were calculated by integrating the DSC peaks.

\section{Transmittance Fourier Transform Infrared Spectroscopy}

Transmittance infrared spectra of NZ, $\mathrm{NH}_{4}-\mathrm{NZ}-15 \mathrm{~h}$, and $\mathrm{H}-\mathrm{NZ}$ were obtained by the standard potassium bromide $(\mathrm{KBr})$ pellet method in the region of $400-4000 \mathrm{~cm}^{-1}$ after 40 scans at $4 \mathrm{~cm}^{-1}$ resolution at room temperature on a spectrometer equipped with a deuterated triglycine sulfate (DTGS) detector (FTS 3000 MX, Digilab Excalibur Series). Prior to the analyses, $1 \mathrm{mg}$ of dehydrated zeolite samples was ground with $150 \mathrm{mg}$ of $\mathrm{KBr}$ and the powder mixtures were pressed into pellets of $13 \mathrm{~mm}$ in diameter under $4 \mathrm{ton} / \mathrm{cm}^{2}$ by a hydraulic press. The absorbance values were normalized with respect to the absorbance of the most intense band in the spectrum.

\section{Temperature-Programmed Diffuse Reflectance Fourier Transform Infrared Spectroscopy}

The dehydration behavior of the samples was determined by an in situ temperature-programmed diffuse reflectance Fourier transform infrared spectroscopy method. The samples were heated in situ from room temperature up to $520^{\circ} \mathrm{C}$ at a heating rate of $1^{\circ} \mathrm{C} / \mathrm{min}$ under vacuum $\left(10^{-6} \mathrm{mbar}\right)$ in a praying mantis diffuse reflection attachment (Harrick Scientific Products Inc., Ossing, NY) equipped with a high-temperature, low-pressure reaction chamber (HVC-DRP, Harrick Scientific Products Inc.). The reaction chamber has two $\mathrm{KBr}$ windows and one glass window for observation. The temperature of the sample in the sample cup of the reaction chamber was measured by a K-type thermocouple and controlled by a low-voltage heating cartridge using a single-loop proportionalintegral-derivative (PID) temperature controller (Series 989, Watlow, Winona, MN). The pressure in the chamber was measured by a Pirani vacuum gauge (measurement range: $5 \times 10^{-4}$ to $1,000 \mathrm{mbar}$, Thermovac TR $216 \mathrm{~S}$, Oerlikon Leybold, Cologne, Germany) and Penning vacuum gauge (measurement range: $10^{-9}$ to $10^{-3}$ mbar, PTR 225, Oerlikon Leybold). The zeolite powders were mixed with $\mathrm{KBr}$ in a ratio of $10 \%(\mathrm{w} / \mathrm{w})$, ground together, and packed into the sample cup. The spectra were recorded at 50 scans at a resolution of $8 \mathrm{~cm}^{-1}$ in the $400-4000 \mathrm{~cm}^{-1}$ range after waiting for $15 \mathrm{~min}$ at each temperature. The background spectra were recorded using $\mathrm{KBr}$. The spectra of the 
samples were also taken after cooling to room temperature under vacuum and opened to the atmosphere after the dehydration experiment.

\section{RESULTS AND DISCUSSION \\ Characterization}

\section{Scanning Electron Microscopy}

From the scanning electron micrographs of NZ (a representative micrograph is shown in Fig. 1), it was observed that NZ is rich in clinoptilolite crystals with a tabular, coffin-like morphology with a characteristic monoclinic symmetry. Treatment with $\mathrm{NH}_{4} \mathrm{OH}$ did not change the crystal morphology.

\section{$X$-ray Powder Diffraction}

The X-ray powder diffractograms of NZ, $\mathrm{NH}_{4}-\mathrm{NZ}-15 \mathrm{~h}$, and subsequently calcined form (H-NZ) are shown in

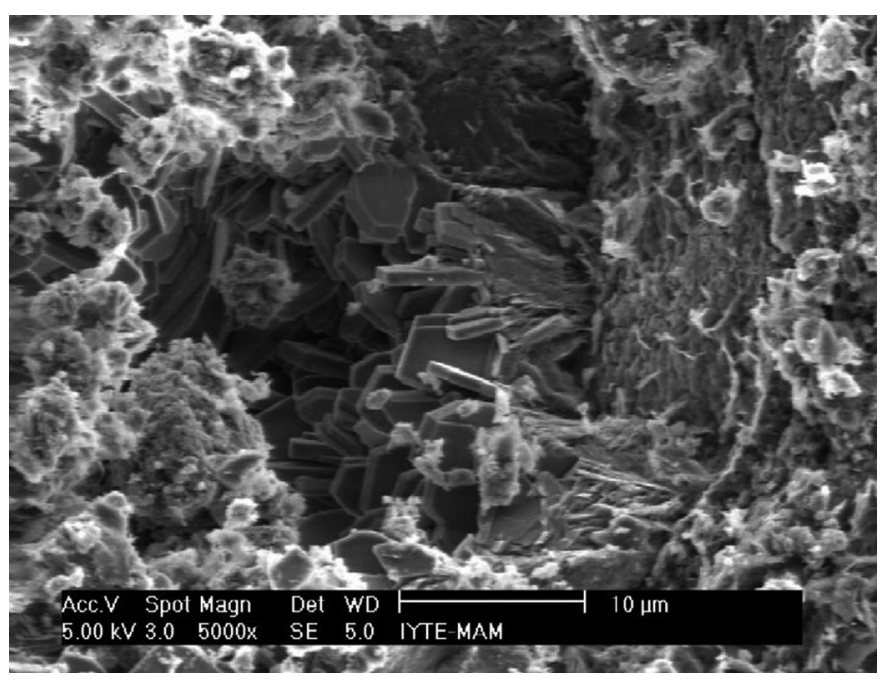

FIG. 1. Representative SEM micrograph of NZ $(\times 5,000)$.

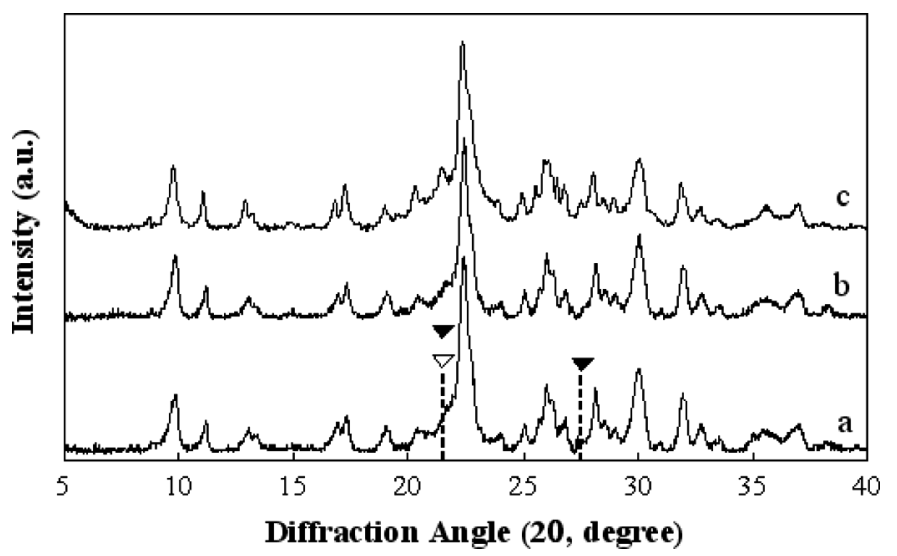

FIG. 2. X-ray powder diffractograms of (a) NZ, (b) $\mathrm{NH}_{4}$-NZ-15h, and (c) H-NZ. $\mathbf{\text { : }}$ quartz, $\nabla$ : cristobalite.
Fig. 2. In the X-ray diffractogram of NZ, the most intense peaks were detected at $9.87^{\circ}, 22.41^{\circ}, 26.05^{\circ}, 28.17^{\circ}, 30.09^{\circ}$, and $32.01^{\circ} 2 \theta$, which belong to the clinoptilolite phase. The qualitative mineralogical analysis revealed that the sample contained predominantly clinoptilolite (JCPDS 80-1557) as well as quartz (JCPDS 83-0540) and cristobalite (JCPDS 76-1390). It was revealed that the $\mathrm{NH}_{4} \mathrm{OH}$ treatment and successive calcination at $500^{\circ} \mathrm{C}$ did not lead to significant changes in the diffraction angles, intensities, and widths of the characteristic peaks of clinoptilolite. The H-NZ was stable; that is, removal of the $\mathrm{NH}_{3}$ from the structure did not lead to collapse of the crystal structure.

The nature, amount, and position of the extraframework cations in clinoptilolite channels affect the intensity of the peak corresponding to the (020) plane of clinoptilolite at $9.87^{\circ} 20$. The unchanged intensity of this band in the X-ray diffractogram of $\mathrm{NH}_{4}-\mathrm{NZ}$ indicated that the cation composition of the zeolite did not change with the $\mathrm{NH}_{4} \mathrm{OH}$ treatment.

\section{Chemical Composition}

The chemical compositions of $\mathrm{NZ}, \mathrm{NH}_{4}-\mathrm{NZ}-15 \mathrm{~h}$, and $\mathrm{H}-\mathrm{NZ}$ determined by ICP-AES and EDS are given in Table 1. It was revealed that $\mathrm{NZ}$ has an $\mathrm{SiO}_{2} / \mathrm{Al}_{2} \mathrm{O}_{3}$ ratio of 6.46, which is typical for clinoptilolite. ${ }^{[4]}$ The theoretical cation exchange capacity (TCEC) of NZ was calculated from the sum of the exchangeable cations $\left(\mathrm{Ca}^{2+}, \mathrm{Mg}^{2+}\right.$, $\mathrm{Na}^{+}$, and $\mathrm{K}^{+}$) as $2.29 \mathrm{meq} / \mathrm{g}$ zeolite. The solid-phase chemical composition analysis revealed that the total cation content of $\mathrm{NZ}$ decreased only by $0.17 \mathrm{meq} / \mathrm{g}$ during the $\mathrm{NH}_{4} \mathrm{OH}$ treatment, considerably lower than the TCEC, indicating that the reaction between the $\mathrm{NZ}$ and $\mathrm{NH}_{4} \mathrm{OH}$ solution could not be explained solely by ion exchange.

The framework ( $\mathrm{Si}$ and $\mathrm{Al})$ and nonframework $(\mathrm{Ca}, \mathrm{Na}$, $\mathrm{K}, \mathrm{Mg}$ ) cation concentration of $\mathrm{NZ}$ did not change significantly with the contact period during the $\mathrm{NH}_{4} \mathrm{OH}$ treatment. The changes in concentration of the species within the initial $5 \mathrm{~h}$ were more significant than those at later times. Thus, $\mathrm{NH}_{4}^{+}$exchange equilibrium was attained within the initial $5 \mathrm{~h}$ period.

The slight decrease in the concentrations of exchangeable cations in the zeolite with the ammonia treatment may be attributed to ion exchange and/or dissolution. However, no significant change was detected in the silicon and aluminum content of the zeolite with the $\mathrm{NH}_{4} \mathrm{OH}$ treatment, implying lack of dissolution of the minor mineral phases accompanying the clinoptilolite. In highly basic solutions, as in the case here, $\mathrm{OH}^{-}$ions in the solution may react with the clinoptilolite surface and caused the surface to be deprotonated ${ }^{[33]}$ :

$$
\equiv \mathrm{Si}-\mathrm{OH}+\mathrm{OH}^{-} \rightleftharpoons \equiv \mathrm{Si}-\mathrm{O}^{-}+\mathrm{H}_{2} \mathrm{O}
$$

The deprotonation of surface $\equiv \mathrm{Si}-\mathrm{OH}$ groups leads to weakening of the $\mathrm{Si}-\mathrm{O}-\mathrm{Si}$ and $\mathrm{Al}-\mathrm{O}-\mathrm{Si}$ bonds on the 
TABLE 1

Oxide compositions of NZ, $\mathrm{NH}_{4}-\mathrm{NZ}$, and $\mathrm{H}-\mathrm{NZ}$ by EDS and ICP (\% w/w)

\begin{tabular}{|c|c|c|c|c|c|c|c|c|c|c|}
\hline \multirow[b]{2}{*}{ Oxides } & \multicolumn{2}{|c|}{$\mathrm{NZ}$} & \multicolumn{2}{|c|}{$\mathrm{NH}_{4}-\mathrm{NZ}-5 \mathrm{~h}$} & \multicolumn{2}{|c|}{$\mathrm{NH}_{4}-\mathrm{NZ}-15 \mathrm{~h}$} & \multicolumn{2}{|c|}{$\mathrm{NH}_{4}-\mathrm{NZ}-45 \mathrm{~h}$} & \multicolumn{2}{|c|}{$\mathrm{H}-\mathrm{NZ}$} \\
\hline & EDS & ICP & EDS & ICP & EDS & ICP & EDS & ICP & EDS & ICP \\
\hline $\mathrm{SiO}_{2}$ & 78.11 & 77.60 & 77.90 & 79.40 & 77.80 & 78.50 & 77.15 & 77.90 & 77.10 & 78.60 \\
\hline $\mathrm{Al}_{2} \mathrm{O}_{3}$ & 12.59 & 12.02 & 11.98 & 11.65 & 11.50 & 11.78 & 11.93 & 12.12 & 13.14 & 11.76 \\
\hline $\mathrm{Na}_{2} \mathrm{O}$ & 1.23 & 2.48 & 1.15 & 2.07 & 1.01 & 2.12 & 1.17 & 2.23 & 1.10 & 2.13 \\
\hline $\mathrm{K}_{2} \mathrm{O}$ & 3.24 & 3.78 & 3.02 & 3.34 & 3.60 & 3.45 & 3.41 & 3.61 & 3.14 & 3.55 \\
\hline $\mathrm{CaO}$ & 3.99 & 3.30 & 4.33 & 2.74 & 4.86 & 3.56 & 5.26 & 3.50 & 3.80 & 3.41 \\
\hline $\mathrm{MgO}$ & 1.34 & 0.02 & 1.60 & 0.02 & 1.25 & 0.02 & 1.09 & 0.02 & 1.90 & 0.02 \\
\hline $\mathrm{MnO}$ & - & 0.71 & - & 0.74 & - & 0.68 & - & 0.65 & - & 0.56 \\
\hline $\mathrm{SiO}_{2} / \mathrm{Al}_{2} \mathrm{O}_{3}$ & 6.20 & 6.46 & 6.50 & 6.82 & 6.76 & 6.65 & 6.46 & 6.42 & 5.86 & 6.68 \\
\hline
\end{tabular}

surface and detachment of $\mathrm{Si}-\mathrm{OH}$. Those deprotonated surface groups $\left(\mathrm{Si}-\mathrm{O}^{-}\right)$behave as Lewis bases and the sorption of cations $\left(\mathrm{M}^{\mathrm{n}+}\right)$ in the solution may lead to complex formation:

$$
\equiv \mathrm{Si}-\mathrm{O}^{-}+\mathrm{M}^{\mathrm{n}+} \rightleftharpoons \equiv \mathrm{Si}-\mathrm{OM}
$$

The adsorption of hydroxyl groups on the zeolite surface during treatment with basic solution has been also reported in the literature. ${ }^{[34]}$

The following equilibrium reactions may occur during the treatment of $\mathrm{NZ}$ with aqueous ammonia solution:

$$
\mathrm{NH}_{3}+\mathrm{H}_{2} \mathrm{O} \rightleftharpoons \mathrm{NH}_{4} \mathrm{OH}
$$

On the other hand, if the $\mathrm{NH}_{4}^{+}$is removed from the system by ion exchange, the equilibrium concentration of $\mathrm{NH}_{4}^{+}$ will be maintained by ionization of $\mathrm{NH}_{4} \mathrm{OH}$ according to the reaction given by:

$$
\begin{gathered}
\mathrm{NH}_{4} \mathrm{OH} \rightleftharpoons \mathrm{NH}_{4}^{+}+\mathrm{OH}^{-} \\
\mathrm{NH}_{4}^{+}+\mathrm{A}^{+}-\mathrm{NZ} \rightleftharpoons \mathrm{NH}_{4}^{+}-\mathrm{NZ}+\mathrm{A}^{+}
\end{gathered}
$$

where A is an exchangeable cation in NZ.

Ammonium hydroxide could also react and neutralize acidic sites of the $\mathrm{NZ}$ giving $\mathrm{NH}_{4}-\mathrm{NZ}$ :

$$
\mathrm{NH}_{4} \mathrm{OH}+\mathrm{H}_{3} \mathrm{O}^{+} \mathrm{NZ} \rightleftharpoons \mathrm{NH}_{4}-\mathrm{NZ}+2 \mathrm{H}_{2} \mathrm{O}
$$

The equilibrium concentrations of $\mathrm{NH}_{3}$ and $\mathrm{NH}_{4}^{+}$species in the solution depend on $\mathrm{pH}$ and temperature of the solution. At $\mathrm{pH}$ values above 9, most of the ammonium is found as $\mathrm{NH}_{3} .{ }^{[4]}$

The chemical compositions determined by the $\mathrm{CHN}$ analysis are reported in Table 2 as $\mathrm{CO}_{3}^{2-}, \mathrm{H}_{2} \mathrm{O}$, and $\mathrm{NH}_{3}$. The acidic site concentration of $\mathrm{NZ}$ was calculated based on the amount of $\mathrm{NH}_{3}$ adsorbed as $0.425 \mathrm{mmol} / \mathrm{g}$ zeolite. Indeed, a natural clinoptilolite from the Bigadiç region of Turkey was titrated with an organic base (diethyl amine) and $0.260-0.430 \mathrm{mmol}$ diethyl amine was neutralized per gram of zeolite depending on the calcination time and temperature. ${ }^{[35]} \mathrm{A}$ very small amount of $\mathrm{CO}_{3}^{-2}$ ions $(0.50-0.95 \%)$ was present in the samples under study. Ammonia-treated samples had higher $\mathrm{CO}_{3}^{-2}$ concentration due to adsorption of dissolved $\mathrm{CO}_{2}$ from air by the aqueous ammonia solution.

\section{Specific Surface Area and Pore Size}

The $\mathrm{N}_{2}$ adsorption-desorption isotherms for NZ and $\mathrm{H}-\mathrm{NZ}$ are presented in Fig. 3, which correspond to Type IV according to IUPAC classification. The hysteresis loops that appeared in the multilayer range of the isotherms is usually associated with capillary condensation in mesopores (secondary porosity). Two types of porosity are present in clinoptilolite: the primary porosity (microporosity)

TABLE 2

$\mathrm{CO}_{3}^{2-}, \mathrm{H}_{2} \mathrm{O}$, and $\mathrm{NH}_{3}$ contents derived from $\mathrm{CHN}$ analysis $(\% \mathrm{w} / \mathrm{w})$

\begin{tabular}{lccccr}
\hline Species & $\mathrm{NZ}$ & $\mathrm{NH}_{4}-\mathrm{NZ}-5 \mathrm{~h}$ & $\mathrm{NH}_{4}-\mathrm{NZ}-15 \mathrm{~h}$ & $\mathrm{NH}_{4}-\mathrm{NZ}-45 \mathrm{~h}$ & $\mathrm{H}-\mathrm{NZ}$ \\
\hline $\mathrm{CO}_{3}^{2-}$ & 0.50 & 0.95 & 0.70 & 0.80 & 0.60 \\
$\mathrm{H}_{2} \mathrm{O}$ & 12.96 & 12.60 & 12.51 & 13.23 & 10.44 \\
$\mathrm{NH}_{3}$ & 0 & 0.59 & 0.57 & 0.61 & 0 \\
\hline
\end{tabular}




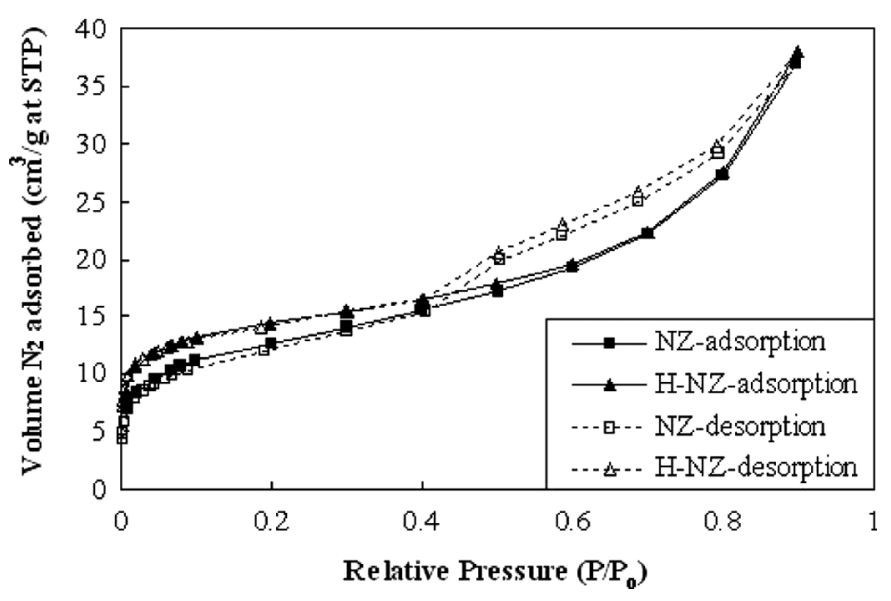

FIG. 3. $\mathrm{N}_{2}$ adsorption and desorption isotherms determined volumetrically at $-196^{\circ} \mathrm{C}$.

results from the crystalline structure of the zeolite. The secondary porosity in the microporous solids is associated with the pores between the crystals and with the presence of the accompanying material in the tuff. The secondary porosity is usually presented by a system of mesopores and macropores. ${ }^{[4]}$ Capillary condensation in the mesopores was observed at a relative pressure $\left(P / P_{o}\right)$ of around 0.4 for both samples. The specific surface areas of $\mathrm{NZ}$ and $\mathrm{H}-\mathrm{NZ}$ were calculated from the linear portion of the Brunauer-Emmett-Teller (BET) plots as 44 and $47 \mathrm{~m}^{2} / \mathrm{g}$, respectively. The average pore diameters $\left(4 \mathrm{~V} / \mathrm{A}_{\mathrm{BET}}\right)$ values were calculated as $4.3 \mathrm{~nm}$ for $\mathrm{NZ}$ and $5.0 \mathrm{~nm}$ for $\mathrm{H}-\mathrm{NZ}$. Because the BET model does not govern the micropore adsorption, the BET surface area was used for comparative purposes. Furthermore, $\mathrm{N}_{2}$ molecules (kinetic diameter of $0.364 \mathrm{~nm}$ ) cannot freely penetrate into the micropores of clinoptilolite. The $\mathrm{NH}_{4} \mathrm{OH}$ treatment and successive calcination process caused a slight increase in the specific surface area and average pore size of NZ, which can be attributed to removal of the mineral impurities from the surface of NZ.

\section{Thermogravimetric Analysis}

The thermogravimetric (TG) curves for $\mathrm{NZ}$ and $\mathrm{NH}_{4}-$ NZ-15h are shown in Fig. 4. The continuous and uninterrupted TG curves indicated that the frameworks were not destroyed by heating up to $1000^{\circ} \mathrm{C}$. The total amount of water loss up to $1000^{\circ} \mathrm{C}$ was determined as $11.6,11.3$, and $11.7 \%(\mathrm{w} / \mathrm{w})$ for $\mathrm{NZ}, \mathrm{NH}_{4}-\mathrm{NZ}-15 \mathrm{~h}$, and $\mathrm{H}-\mathrm{NZ}$, respectively, indicating that the $\mathrm{NH}_{4} \mathrm{OH}$ treatment and successive heat treatment had no significant effect on the water adsorption capacity of the zeolite except for differences in the water loss in certain temperature ranges.

When the $\mathrm{H}$ content determined by the elemental analyzer was converted to equivalent $\mathrm{H}_{2} \mathrm{O}$, it was nearly

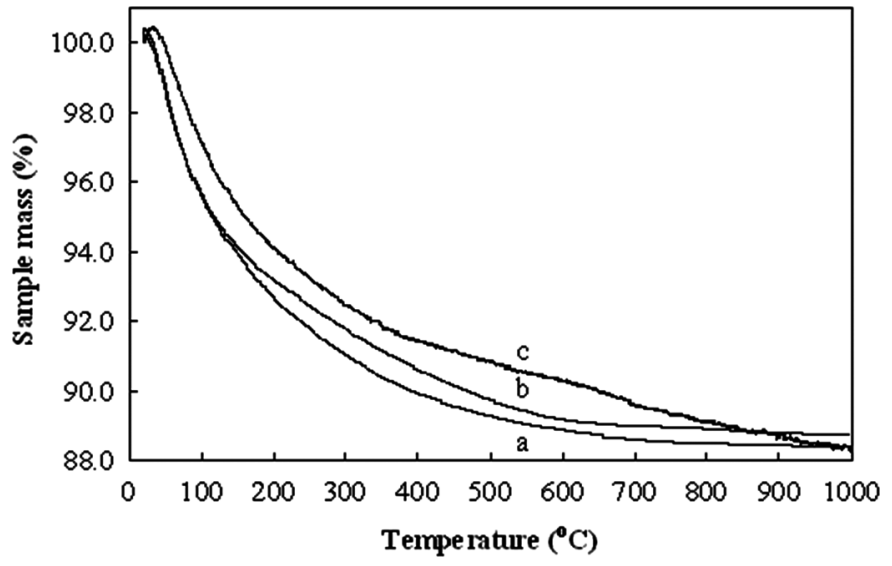

FIG. 4. TG curves for (a) NZ, (b) $\mathrm{NH}_{4}-\mathrm{NZ}-15 \mathrm{~h}$, and (c) H-NZ.

$12 \%(\mathrm{w} / \mathrm{w})$ as given in Table 2 . Thus, both TGA and elemental analysis gave consistent results for the $\mathrm{H}_{2} \mathrm{O}$ content.

The TG curves showed that the weight loss occurred in a stepwise manner for all samples. In order to distinguish the different types of water present in the zeolites, the TG curves were analyzed according to the procedure outlined in the literature. ${ }^{[2]}$ The low-temperature inflection point was observed at around $100^{\circ} \mathrm{C}$ for NZ. The rapid weight loss up to this temperature $(4.4 \% \mathrm{w} / \mathrm{w})$ was due to desorption of the externally adsorbed water. Another inflection point was detected at about $280^{\circ} \mathrm{C}$ for $\mathrm{NZ}$ and assigned to desorption of the loosely bound water $(4.2 \% \mathrm{w} / \mathrm{w})$. Above $280^{\circ} \mathrm{C}$, slow desorption of the tightly bound water took place $(2.9 \% \mathrm{w} / \mathrm{w})$. The differences in the temperature of the inflection points from those reported in the literature can be attributed to the experimental conditions under which the dehydration was performed such as heating rate, atmosphere over the sample, preparation of the sample, and type of technique employed. ${ }^{[2]}$

The TG curve of $\mathrm{NH}_{4}-\mathrm{NZ}-15 \mathrm{~h}$ exhibited a different trend in the temperature range of $125-600^{\circ} \mathrm{C}$. In this range, $\mathrm{NH}_{4}$-NZ-15h lost less weight than NZ. It was not possible to observe two steps related to deammoniation and dehydroxylation during the thermal decomposition of $\mathrm{NH}_{4^{-}}$ NZ-15h.

\section{Differential Scanning Calorimetry}

The DSC curves, with baseline drift subtracted, are shown in Fig. 5. In the DSC curve for NZ, two endothermic peaks were detected at 70 and $182^{\circ} \mathrm{C}$. The other samples exhibited one endothermic peak at $70^{\circ} \mathrm{C}$. These endothermic peaks were connected with elimination of the externally adsorbed water. The second endothermic peak in the DSC curve of NZ was attributed to desorption of the loosely bound zeolite water. ${ }^{[2]}$ 


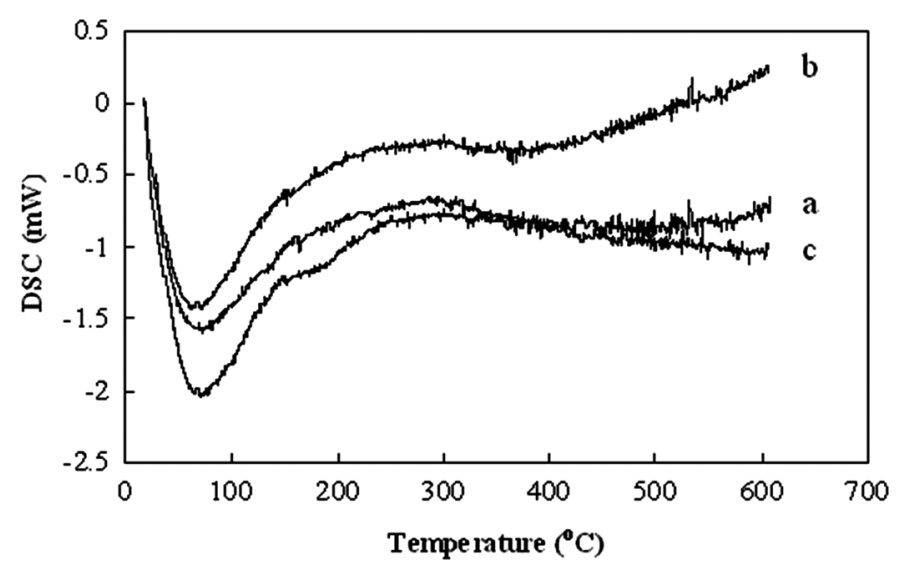

FIG. 5. DSC curves for (a) NZ, (b) NH4-NZ-15h, and (c) H-NZ.

Integrating the DSC peaks, the heats of dehydration values were calculated as 144,74 , and $170 \mathrm{~kJ} / \mathrm{mol} \mathrm{H}_{2} \mathrm{O}$ for $\mathrm{NZ}, \mathrm{NH}_{4}-\mathrm{NZ}-15 \mathrm{~h}$, and $\mathrm{H}-\mathrm{NZ}$, respectively, and were found to be in agreement with the previously reported values, ${ }^{[2,25,26]}$ but higher than those determined by DSC. ${ }^{[27]}$ The DSC peaks were also integrated numerically in the temperature ranges of $25-100^{\circ} \mathrm{C}, 100-200^{\circ} \mathrm{C}$, and $200-300^{\circ} \mathrm{C}$ in order to determine the heats of dehydration at different surface coverages. These heat values agreed well with the previously reported values determined by microcalorimetry. ${ }^{[2,26]}$ The heats of dehydration values for $\mathrm{NH}_{4}-\mathrm{NZ}-15 \mathrm{~h}$ were lower than those for the other samples in all temperature ranges. The surface coverage values were determined based on the TGA data and change of the heats of dehydration with the surface coverage was shown in Fig. 6. The heats of dehydration decreased with the surface coverage for NZ and $\mathrm{H}-\mathrm{NZ}$ as reported in the literature, ${ }^{[25,26]}$ whereas it was almost independent of the surface coverage for $\mathrm{NH}_{4}-\mathrm{NZ}-15 \mathrm{~h}$. This indicated that in DSC analysis of $\mathrm{NH}_{4}-\mathrm{NZ}-15 \mathrm{~h}$, the enthalpy changes

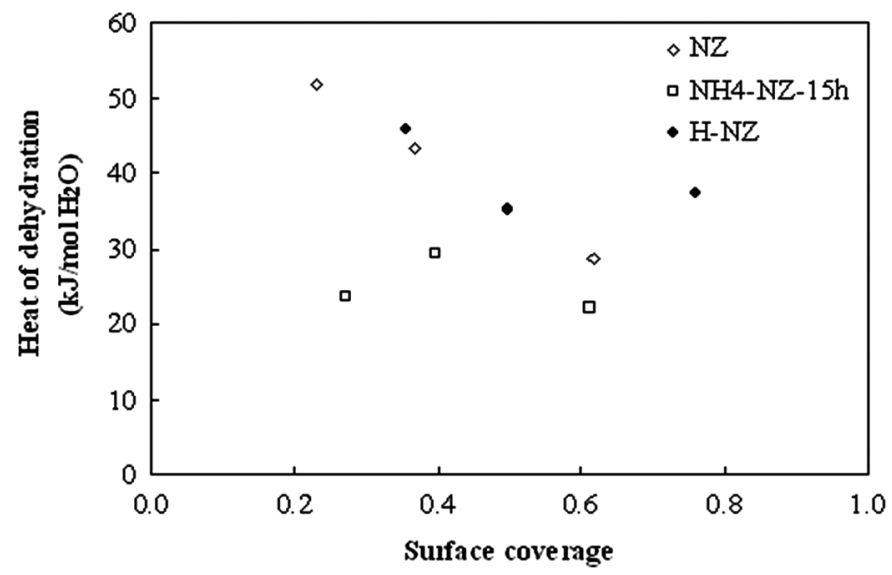

FIG. 6. Change of the heat of dehydration with surface coverage. recorded were not due to endothermic dehydration but to some exothermic rearrangements in the structure occurring at high temperatures corresponding to removal of isolated $\mathrm{OH}$ groups. The decrease in the dehydration heat with the surface coverage could be explained by retention of water molecules more tightly by the cations at low surface coverages. ${ }^{[9]}$

\section{Transmittance Fourier Transform Infrared Spectroscopy}

The transmittance infrared spectra of the samples recorded under atmospheric conditions are shown in Fig. 7. The bands detected in the range of $1200-400 \mathrm{~cm}^{-1}$ are assigned to the internal stretching vibrations of $\mathrm{Si}-\mathrm{O}(\mathrm{Si})$ and $\mathrm{Si}-\mathrm{O}(\mathrm{Al})$ in the tetrahedra. In this range bands were detected at 473,530,609,677, 737, 795, and $1063 \mathrm{~cm}^{-1}$. The strongest band appearing at $1063 \mathrm{~cm}^{-1}$ was attributed to asymmetric O-T-O stretching vibration. This band shifted to $1070 \mathrm{~cm}^{-1}$ for $\mathrm{H}-\mathrm{NZ}$, indicating distortion of the framework.

The intensity of the $473 \mathrm{~cm}^{-1}$ band is related to the nature and position of the cations in the zeolite structure. The comparison of the intensity of this band with those pseudolattice bands $\left(500-700 \mathrm{~cm}^{-1}\right)$ is used to determine the degree of amorphization in zeolites. The band at $530 \mathrm{~cm}^{-1}$ is related to pore opening vibrations. This band could not have been detected in the spectrum of H-NZ. The band at $609 \mathrm{~cm}^{-1}$ is due to stretching of the internal tetrahedral bonds and is typical for the ordered crystal structure of clinoptilolite. The position of this band is related to the clinoptilolite content of the mineral. The intensity of this band in the spectrum of $\mathrm{H}-\mathrm{NZ}$ decreased. The $\mathrm{NH}_{4} \mathrm{OH}$ treatment and subsequent heating did not affect the band at $677 \mathrm{~cm}^{-1}$. This band is due to symmetrical stretching vibrations of the $\mathrm{Si}-\mathrm{O}$ bond existing in the 6-membered rings of the zeolite and is sensitive to changes in the type

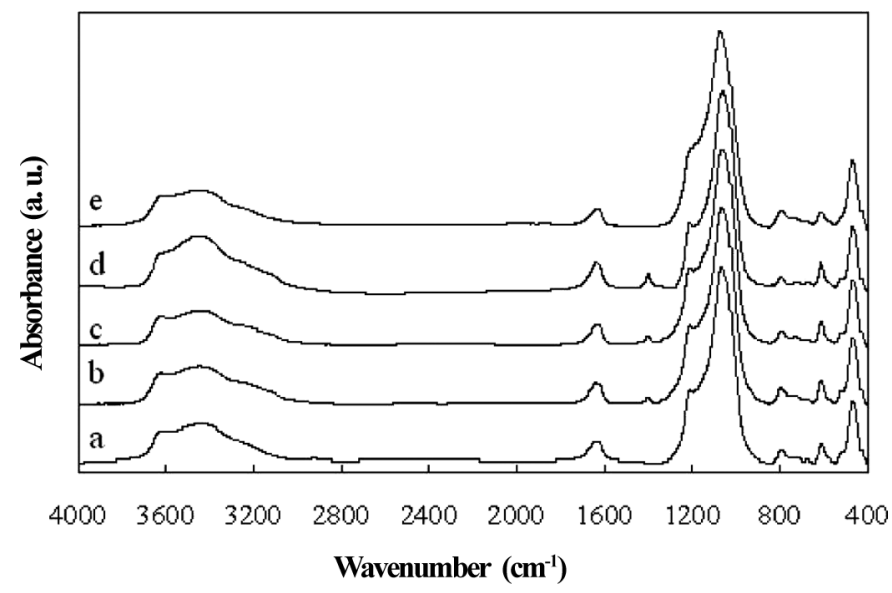

FIG. 7. Transmittance infrared spectra of the samples recorded under atmospheric conditions for (a) NZ, (b) $\mathrm{NH}_{4}-\mathrm{NZ}-5 \mathrm{~h}$, (c) $\mathrm{NH}_{4}-\mathrm{NZ}-15 \mathrm{~h}$, (d) $\mathrm{NH}_{4}-\mathrm{NZ}-45 \mathrm{~h}$, and (e) H-NZ. 
and amount of nontetrahedral cations. The bands at 737 and $795 \mathrm{~cm}^{-1}$ are due to vibrations of the $\mathrm{Si}-\mathrm{O}-\mathrm{Al}$ and $\mathrm{Si}-\mathrm{O}-\mathrm{Si}$ bonds, respectively. The shoulder at $1209 \mathrm{~cm}^{-1}$ is due to asymmetric stretching vibrations of $\mathrm{T}-\mathrm{O}$ bonds. This band has become less prominent in the spectrum of $\mathrm{H}-\mathrm{NZ}$. The vibrations in the region $1600-3700 \mathrm{~cm}^{-1}$ are assigned to the presence of water. The isolated band at $1635 \mathrm{~cm}^{-1}$ is due to bending vibration of sorbed water. In the $\mathrm{O}-\mathrm{H}$ stretching region $\left(3000-3700 \mathrm{~cm}^{-1}\right)$, a broad band with two maxima at 3445 and $3620 \mathrm{~cm}^{-1}$ and a shoulder at $3250 \mathrm{~cm}^{-1}$ were detected related with stretching vibrations of hydroxyl groups. No remarkable changes were observed in either intensities or frequencies of the bands in the $\mathrm{O}-\mathrm{H}$ stretching region upon the $\mathrm{NH}_{4} \mathrm{OH}$ treatment and subsequent heating.

After the $\mathrm{NH}_{4} \mathrm{OH}$ treatment, a new shoulder appeared at $3134 \mathrm{~cm}^{-1}$ and it was assigned to N-H stretching vibrations. ${ }^{[31]}$ Also, an isolated band at $1402 \mathrm{~cm}^{-1}$ was detected in the spectrum after the $\mathrm{NH}_{4} \mathrm{OH}$ treatment. Both bands disappeared after heating the sample at $500^{\circ} \mathrm{C}$ for $5 \mathrm{~h}$. The band at $1402 \mathrm{~cm}^{-1}$ is close to the vibrations of the $\mathrm{N}-\mathrm{H}$ bending centered at $1450 \mathrm{~cm}^{-1}$. No significant change was observed in the intensity of the $3134 \mathrm{~cm}^{-1}$ band with the $\mathrm{NH}_{4} \mathrm{OH}$ treatment period. The intensity of the $3445 \mathrm{~cm}^{-1}$ band inclined remarkably after the $\mathrm{NH}_{4} \mathrm{OH}$ treatment for $45 \mathrm{~h}$. This band is assigned to vibrations of the hydrogen bonds between water molecules and framework oxygen atoms.

The area of the $1402 \mathrm{~cm}^{-1}$ band increased proportionally with the $\mathrm{NH}_{4} \mathrm{OH}$ treatment period (Table 3). On the other hand, the ammonia content of the $\mathrm{NH}_{4}-\mathrm{NZ}$ samples, reported in Table 2, did not change significantly with the treatment period based on the $\mathrm{CHN}$ analysis,

\section{Temperature-Programmed Diffuse Reflectance Fourier Transform Infrared Spectroscopy}

The DRIFT spectra of $\mathrm{NZ}$ and its $\mathrm{NH}_{4} \mathrm{OH}$-treated and subsequently calcined forms recorded during in situ heating under vacuum are illustrated in Figs. 8-10, respectively. In the DRIFT spectra of the samples recorded at room temperature before vacuum, a broad band in the range of

TABLE 3

Area of $1402 \mathrm{~cm}^{-1}$ band for the sample treated for different periods with $\mathrm{NH}_{4} \mathrm{OH}$

\begin{tabular}{lcc}
\hline Sample & $\begin{array}{c}\mathrm{NH}_{4} \mathrm{OH} \text { treatment } \\
\text { period }(\mathrm{h})\end{array}$ & $\begin{array}{c}1402 \mathrm{~cm}^{-1} \\
\text { band area }\end{array}$ \\
\hline $\mathrm{NZ}$ & 0 & 0 \\
$\mathrm{NH}_{4}$-NZ-5h & 5 & 1.442 \\
$\mathrm{NH}_{4}$-NZ-15h & 15 & 1.904 \\
$\mathrm{NH}_{4}$-NZ-45h & 45 & 4.500 \\
\hline
\end{tabular}

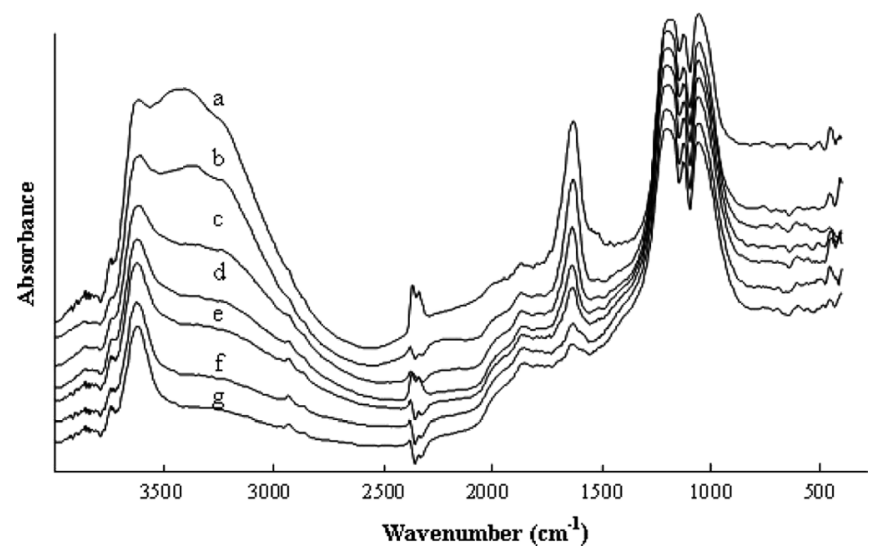

FIG. 8. DRIFT spectra for NZ: (a) before vacuum at $20^{\circ} \mathrm{C}$, (b) under vacuum at $20^{\circ} \mathrm{C}$, (c) at $132^{\circ} \mathrm{C}$, (d) at $225^{\circ} \mathrm{C}$, (e) at $301^{\circ} \mathrm{C}$, (f) at $402^{\circ} \mathrm{C}$; and $(\mathrm{g})$ at $470^{\circ} \mathrm{C}$.

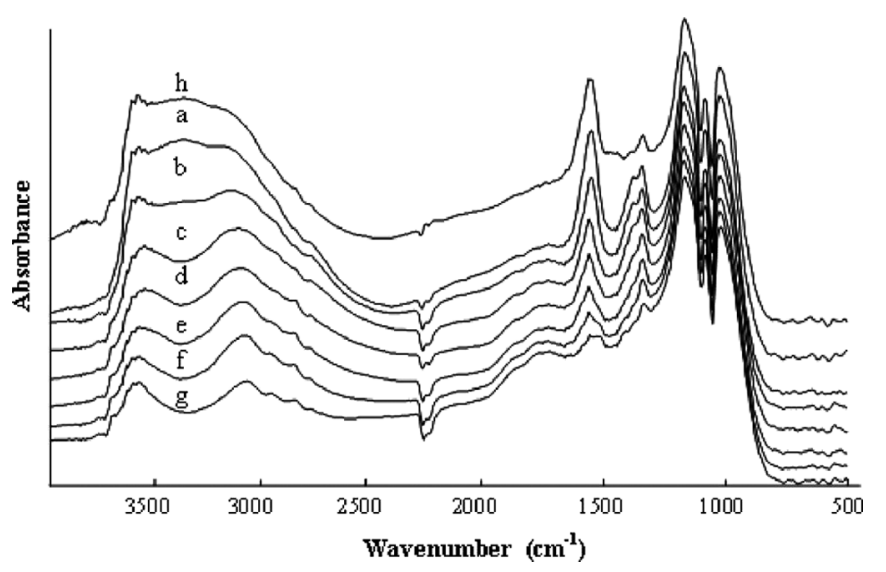

FIG. 9. DRIFT spectra for $\mathrm{NH}_{4}$-NZ-15h: (a) efore vacuum at $24^{\circ} \mathrm{C}$, (b) under vacuum at $24^{\circ} \mathrm{C}$, (c) at $130^{\circ} \mathrm{C}$, (d) at $230^{\circ} \mathrm{C}$, (e) at $323^{\circ} \mathrm{C}$, (f) at $410^{\circ} \mathrm{C}$; (g) at $520^{\circ} \mathrm{C}$, and (h) after open to the atmosphere at $24^{\circ} \mathrm{C}$.

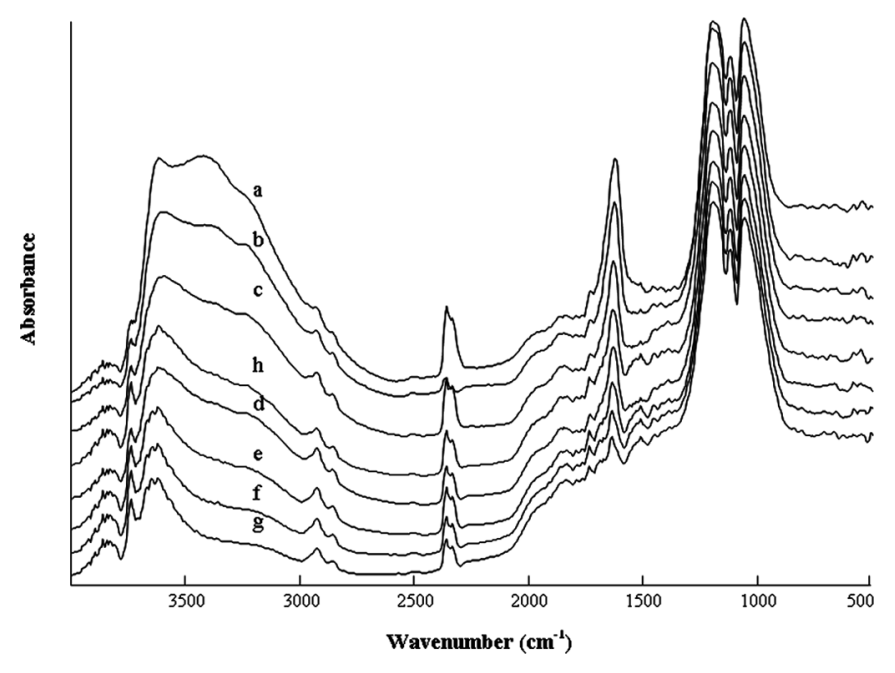

FIG. 10. DRIFT spectra for H-NZ: (a) before vacuum at $20^{\circ} \mathrm{C}$, (b) under vacuum at $20^{\circ} \mathrm{C}$, (c) at $120^{\circ} \mathrm{C}$, (d) at $215^{\circ} \mathrm{C}$, (e) at $305^{\circ} \mathrm{C}$; (f) at $402^{\circ} \mathrm{C}$; (g) at $487^{\circ} \mathrm{C}$, and (h) at $150^{\circ} \mathrm{C}$ after heated to $487^{\circ} \mathrm{C}$. 
$2500-3800 \mathrm{~cm}^{-1}$ was observed that was probably due to the abundance of water molecules present on the surface, which obscures the isolated $\mathrm{OH}$ stretching band. ${ }^{[13]} \mathrm{Com}$ mon bands were detected at 3610, 3410, 3230, 2920, 1630, 1200,1140 , and $1060 \mathrm{~cm}^{-1}$ in the spectra of the samples recorded under these conditions.

In the DRIFT spectra of NZ, the intensities and frequencies of the bands at $3850,3750,1890$, and $2000 \mathrm{~cm}^{-1}$ did not change significantly with temperature. The band at $1510 \mathrm{~cm}^{-1}$ lost intensity with increase in the temperature and disappeared at $402^{\circ} \mathrm{C}$. The band at $2920 \mathrm{~cm}^{-1}$ became more prominent as the temperature increased.

In the DRIFT spectrum of $\mathrm{NH}_{4}-\mathrm{NZ}-15 \mathrm{~h}$ recorded at room temperature, no bands were detected at 1510, 1890, 2000, 3750, and $3850 \mathrm{~cm}^{-1}$. The bands at 1890 and $2000 \mathrm{~cm}^{-1}$ appeared as the temperature increased and disappeared from the spectra when the sample was opened to the atmosphere after heating. The $3750 \mathrm{~cm}^{-1}$ band became visible with the increase in temperature and remained in the spectrum after the sample was opened to the atmosphere. The bands at 1510 and $3850 \mathrm{~cm}^{-1}$ were detected after $\mathrm{NH}_{4}-\mathrm{NZ}-15 \mathrm{~h}$ was opened to the atmosphere after heating. The spectrum recorded after $\mathrm{NH}_{4}-\mathrm{NZ}-15 \mathrm{~h}$ was open to the atmosphere following heating at $520^{\circ} \mathrm{C}$ revealed that the dehydration of $\mathrm{NH}_{4}-\mathrm{NZ}-15 \mathrm{~h}$ was reversible and did not cause irreversible changes in the framework structure. $\mathrm{NH}_{4}-\mathrm{NZ}-15 \mathrm{~h}$ exhibited an extra band at $1402 \mathrm{~cm}^{-1}$ and two shoulders at 1450 and $3030 \mathrm{~cm}^{-1}$. The band at $1450 \mathrm{~cm}^{-1}$ lost intensity with an increase in temperature and disappeared when the sample was heated to $520^{\circ} \mathrm{C}$. The band at $1402 \mathrm{~cm}^{-1}$ was still detectable in the spectrum at $520^{\circ} \mathrm{C}$ and after the sample was opened to the atmosphere. The relative intensities of the 1402 and $1450 \mathrm{~cm}^{-1}$ bands decreased linearly with increasing temperature as shown in Fig. 11. The band at $3030 \mathrm{~cm}^{-1}$ lost

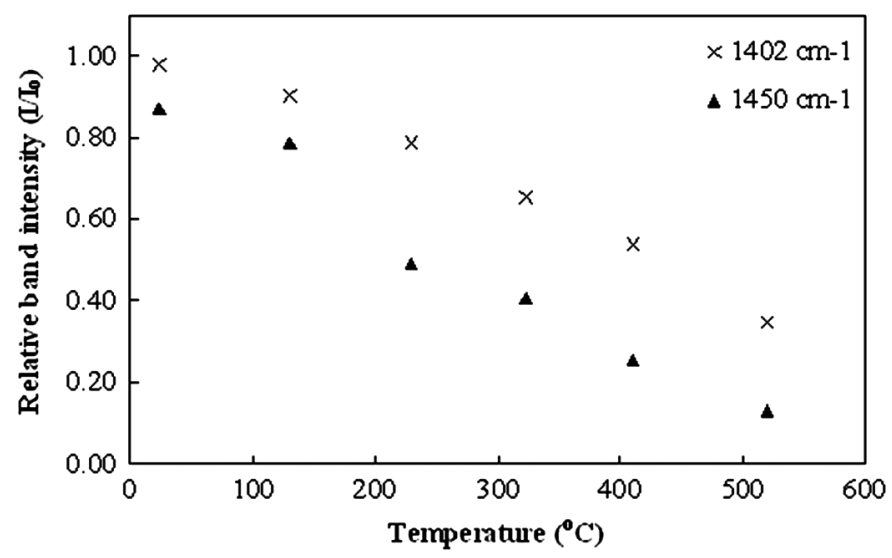

FIG. 11. Change in relative band intensities with temperature for $\mathrm{NH}_{4}$ NZ-15h. intensity and became more prominent as the temperature increased.

In contrast to the transmittance spectrum of $\mathrm{NH}_{4}$ NZ-15h zeolite, the detection of the bands at 1402 and $3030 \mathrm{~cm}^{-1}$ in the spectrum after heating the sample to $520^{\circ} \mathrm{C}$ indicated that the ammonia could not have been removed after heating under vacuum. On the other hand, these bands were not detected in the spectra of H-NZ recorded at room temperature before the evacuation. This implied that the ammonia could be removed from $\mathrm{NH}_{4}$ $\mathrm{NZ}-15 \mathrm{~h}$ when the sample was heated in the presence of air and air is required to remove the ammonia from the structure. ${ }^{[36]}$ Furthermore, because the sensor used to measure the temperature of the sample in the sample holder is located at the bottom of the holder, the temperature of the sample at the depth that the infrared (IR) beam can penetrate may not be as high as that measured at the bottom. Therefore, the ammonia present in the sample could not have been removed. In order to confirm this, $\mathrm{NH}_{4}$ NZ-15h was removed from the sample holder after heating under vacuum and repacked in the holder and reanalyzed. In this case, the bands at 1402 and $3030 \mathrm{~cm}^{-1}$ were not detected.

In the DRIFT spectra of $\mathrm{H}-\mathrm{NZ}$, the band at $3850 \mathrm{~cm}^{-1}$ was not affected by temperature increase and evacuation. The band at $3750 \mathrm{~cm}^{-1}$ became more prominent as the temperature increased. This band is due to surface silanol (terminal) $\mathrm{OH}$ groups. The band at $2920 \mathrm{~cm}^{-1}$ was more significant in the spectrum of $\mathrm{H}-\mathrm{NZ}$ recorded at room temperature before the evacuation compared to the other samples. The intensities and frequencies of the bands at 1890 and $2000 \mathrm{~cm}^{-1}$ did not change significantly with temperature. Different from NZ and $\mathrm{NH}_{4}-\mathrm{NZ}-15 \mathrm{~h}$, an extra band at $1720 \mathrm{~cm}^{-1}$ was observed in the spectra of $\mathrm{H}-\mathrm{NZ}$ at room temperature. Neither intensity nor frequency of this band changed significantly with temperature and evacuation. In the region of $1700-2200 \mathrm{~cm}^{-1}$, overtone framework $\mathrm{Si}-\mathrm{O}$ bands were observed in the IR spectrum of $\mathrm{NH}_{4}-$ analcime. ${ }^{[37]}$

Furthermore, a band appeared at $1510 \mathrm{~cm}^{-1}$ when $\mathrm{H}-\mathrm{NZ}$ was heated to $402^{\circ} \mathrm{C}$. The intensity or frequency of this band was not affected by a further increase in the temperature and continued to be detectable when $\mathrm{H}-\mathrm{NZ}$ was cooled down to $150^{\circ} \mathrm{C}$ and opened to the atmosphere. This band could be due to the presence of carbonate ions in the tuff.

All samples exhibited common bands at 3610, 3410, 3230 , and $1630 \mathrm{~cm}^{-1}$, which are associated with water. The sharp band detected near $3610 \mathrm{~cm}^{-1}$ is assigned to typical stretching vibrations of isolated $\mathrm{OH}$ groups due to interaction of the hydroxyl of the water and the extraframework cations. The broad band at around $3410 \mathrm{~cm}^{-1}$ is characteristic for vibrations of $\mathrm{OH}$ groups bound to the framework oxygen atoms with hydrogen bonds. The band 
at around $1630 \mathrm{~cm}^{-1}$ is assigned to the usual bending vibration of water.

At room temperature, before evacuation, the band at $3610 \mathrm{~cm}^{-1}$ appeared with single maximum in the spectra of NZ and $\mathrm{H}-\mathrm{NZ}$ and with triple maxima in that of $\mathrm{NH}_{4}$-NZ-15h $\left(3650,3610,3590 \mathrm{~cm}^{-1}\right)$. The change in the shape of the $3610 \mathrm{~cm}^{-1}$ band detected in the spectra of $\mathrm{NH}_{4}$-NZ-15h upon heating was found to be different from that for NZ. This band did not become as sharp upon heating as that for NZ. This might indicate the presence of different $\mathrm{OH}$ groups in $\mathrm{NH}_{4}-\mathrm{NZ}-15 \mathrm{~h}$. During deammoniation of zeolite $\mathrm{Y}$, the $\mathrm{OH}$ groups produced gave rise to two IR bands: one at $3640 \mathrm{~cm}^{-1}$, referred to as the high-frequency (HF) band, and a second, low-frequency (LF) band, at $3540 \mathrm{~cm}^{-1}$. These bands were attributed to the location of hydrogen atoms on two different oxygen atoms in the framework. The HF band was attributed to the $\mathrm{H}$ atom located within the large supercages and accessible to adsorbed molecules. The other $\mathrm{H}$ atom giving the LF band was less accessible and probably hidden within the $\beta$-cages of the structure. ${ }^{[34]}$

For NZ and $\mathrm{H}-\mathrm{NZ}$, the band at $3410 \mathrm{~cm}^{-1}$ shifted to $3350 \mathrm{~cm}^{-1}$ as the temperature increased and disappeared above $150^{\circ} \mathrm{C}$. This shift can be attributed to an increase in the strength of the hydrogen bonds between water molecules and the framework oxygen atoms (due to a decrease in the distance between water molecules and the framework oxygen atoms). This band vanished from the spectrum of $\mathrm{NH}_{4}$-NZ-15h after evacuation at room temperature but reappeared in the spectra at the same frequency after the sample was opened to the atmosphere subsequent to heating. This indicated that dehydration of this sample was reversible; that is, the framework did not collapse.

For $\mathrm{NH}_{4}-\mathrm{NZ}-15 \mathrm{~h}$, the band at $3230 \mathrm{~cm}^{-1}$ showed a very different behavior upon heating compared to those in the spectra of $\mathrm{NZ}$ and $\mathrm{H}-\mathrm{NZ}$. In the spectrum of $\mathrm{NH}_{4^{-}}$ $\mathrm{NZ}-15 \mathrm{~h}$, this band shifted to $3200 \mathrm{~cm}^{-1}$ when the sample was evacuated at room temperature. The band further shifted to lower wavenumbers when the temperature increased to $323^{\circ} \mathrm{C}$. This shift indicated an increase in the bond strength with decreasing water content. ${ }^{[9]}$ Above this temperature no change was observed in its position as its intensity continued to decline. The band turned to $3230 \mathrm{~cm}^{-1}$ after the sample was opened to the atmosphere. For NZ and $\mathrm{H}-\mathrm{NZ}$, the band at $3230 \mathrm{~cm}^{-1}$ lost intensity with an increase in the temperature without a change in its position.

For all samples, the relative intensities of the 1630, 3610, 3410 , and $3230 \mathrm{~cm}^{-1}$ bands were found to decrease with increase in the temperature as shown in Fig. 12. The relative band intensity $\left(I / I_{o}\right)$ was calculated by dividing the band intensity at each temperature by that in the spectrum of the zeolite at the fully hydrated state $\left(I_{o}\right)$; that is, at room temperature, before evacuation.
The intensities of the bands at 1630 and $3410 \mathrm{~cm}^{-1}$ decreased in the same extent with temperature for all samples. This might means that these bands are related to water molecules bound to the zeolite in the same way. The former band was assigned to usual bending vibration of water. This band did not disappear even at $520^{\circ} \mathrm{C}$ under $10^{-6} \mathrm{mbar}$ vacuum, indicating the presence of molecular water in the zeolite. The latter band was associated with the vibrations of $\mathrm{OH}$ groups bonded to the surface oxygen atoms via hydrogen bonds. ${ }^{[28]}$ This band was assigned to loosely held water $\left(\mathrm{H}_{2} \mathrm{O}^{-}\right)^{[9]}$ and to vibration of the $\mathrm{O}-\mathrm{H} \cdots \mathrm{O}$ bands. ${ }^{[38]}$ It was reported that hydrogen bond strength of hydrogen-bonded $\mathrm{OH}$ groups varied with the surface coverage. ${ }^{[28]}$

The band at $3610 \mathrm{~cm}^{-1}$ declined in a more gradual manner with temperature compared to the other bands. Moreover, the samples exhibited different trends from each other regarding the decrease in the intensity of this band with temperature. This band was assigned to isolated $\mathrm{OH}$ stretching vibrations, ${ }^{[28]}$ due to interaction of the hydroxyl of the water and the extraframework cations ${ }^{[34]}$ and to tightly held water $\left(\mathrm{H}_{2} \mathrm{O}^{+}\right) \cdot{ }^{[9]}$

For $\mathrm{NZ}$ and $\mathrm{H}-\mathrm{NZ}$, the intensity of the band at $3230 \mathrm{~cm}^{-1}$ decreased with temperature in a trend similar to the other bands, whereas for $\mathrm{NH}_{4}-\mathrm{NZ}-15 \mathrm{~h}$, its intensity declined more slowly. This band is in the region of stretching vibrations of $\mathrm{OH}$ groups.

For clinoptilolite, hydroxyl groups connected to the framework with chemical bonds are absent; thus, the hydroxyl groups are specific for water. ${ }^{[28]}$ The vibrations in the $1600-3700 \mathrm{~cm}^{-1}$ region of the spectrum are due to presence of water in the zeolite. Within the zeolitic pores, the water molecules may interact with the extraframework cations (interaction of the lone pair electrons of the oxygen atom of water with the cations) via ion-dipole interaction with the zeolite framework (to the surface oxygen atoms) via hydrogen bonding and/or with the previously adsorbed water molecules. ${ }^{[28]}$ In large-pore zeolites, all of the types of interactions mentioned above are possible. But in small-pore zeolites the water-water interactions are eliminated and thus the nearest neighbors for each water molecule are the cations and the surface oxygen atoms, for which the hydrogen bonding is weaker. ${ }^{[37,39]}$ The interaction of water with the cations, if both hydrogens were left free, gives two sharp bands in the $\mathrm{OH}$ stretching region. The spectra that contain one sharp band together with a typical hydrogen-bonded band suggest a simultaneous adsorption of water via one set of lone-pair electrons to the exchangeable cation and via one hydrogen-to-surface oxygen atom, leaving the other hydrogen projecting freely into the cavity. ${ }^{[39]}$ The interactions between the framework and the cations also impact the behavior of the water molecules in the pores of the zeolite. ${ }^{[28]}$ 

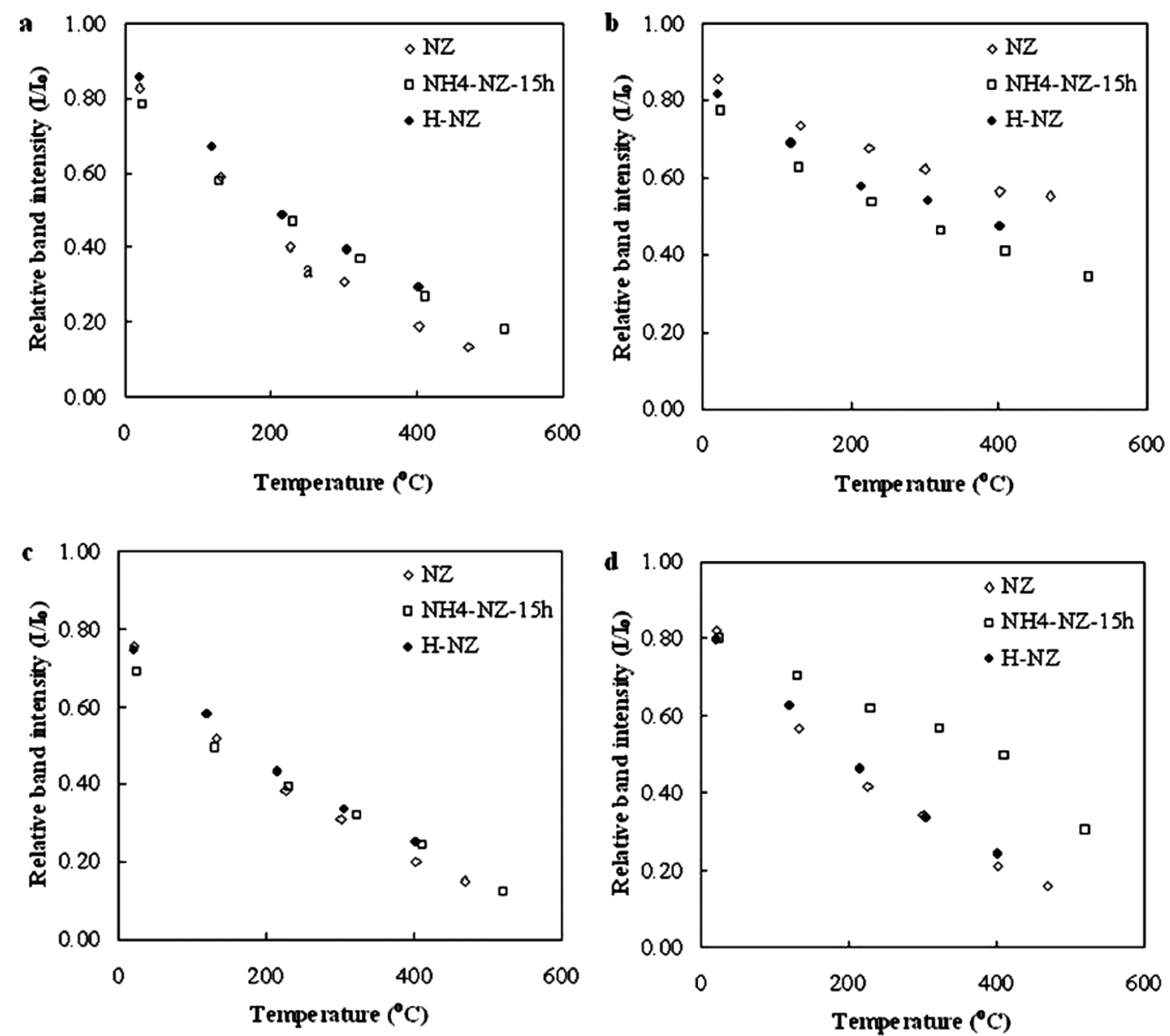

FIG. 12. Change in relative band intensities with temperature: (a) $1630 \mathrm{~cm}^{-1}$, (b) $3610 \mathrm{~cm}^{-1}$, (c) $3410 \mathrm{~cm}^{-1}$, and (d) $3230 \mathrm{~cm}^{-1}$.

The bands at 3610 and $3410 \mathrm{~cm}^{-1}$ could be regarded as corresponding to two different species of adsorbed water with slightly different hydrogen bonds. ${ }^{[9]}$ These bands were assigned to the tightly bound and loosely held water in clinoptilolite, respectively. On the other hand, assignment of the bands in this way is contrary to that normally expected with the hydrogen bonding of water molecules where hydroxyl stretching frequencies normally decrease as bond strength increases. ${ }^{[9]}$ At higher coverages, the free hydrogen would probably become increasingly bonded to adjacent water molecules and a greater proportion of the water would be hydrogen-bonded to the surface oxygen.$^{[9]}$ During dehydration, the hydrogen-bonded water molecules are converted to isolated $\mathrm{OH}$ groups. At low water content, the water molecules might be retained more tightly by the cations and the hydrogen bonds between the water molecules were lengthened (leading the hydrogen bond to become weaker) ${ }^{\left[{ }^{9]}\right.}$ Similarly, different retentions of water in heulandite were attributed to the cation-to-water bond distances ${ }^{[40]}$ and to occupancy values of water molecules and a thermal parameter in clinoptilolite. ${ }^{[2]}$ Higher occupancy values of water molecules and lower thermal parameters indicated stronger bonding. ${ }^{[2]}$

\section{CONCLUSION}

The zeolitic tuff used in the study was rich in clinoptilolite as shown by SEM and X-ray diffraction. Its $\mathrm{SiO}_{2} /$ $\mathrm{Al}_{2} \mathrm{O}_{3}$ ratio was 6.5 and did not change with the ammonia treatment. The chemical compositions of the natural, ammonia-treated, and successively calcined zeolites were nearly identical as determined by ICP and EDX analysis. Based on the $\mathrm{CHN}$ analysis, it was found that the natural zeolite adsorbed $0.425 \mathrm{mmol} \mathrm{NH}_{3} / \mathrm{g}$, indicating the concentration of the Brönsted acid sites. Thus, the zeolitic tuff investigated in the present study could be used as low-level Brönsted acid catalyst in heterogeneous reactions.

The relative intensities of the 1402 and $1450 \mathrm{~cm}^{-1}$ bands of $\mathrm{NH}_{4}$-NZ-15h decreased linearly with increasing temperature, indicating that $\mathrm{NH}_{3}$ was removed by heating the sample. The dehydration of the zeolitic tuff was reversible as shown by the DRIFTS studies. The desorption of the hydrogen-bonded water molecules occurred at lower 
temperatures compared to the isolated $\mathrm{OH}$ groups, which could not be desorbed even at $520^{\circ} \mathrm{C}$ under $10^{-6} \mathrm{mbar}$ vacuum.

The tuff adsorbed $12 \%(\mathrm{w} / \mathrm{w})$ water vapor from air as understood by TGA analysis and elemental analysis. In the DSC curve of NZ, two endothermic peaks were detected at 70 and $182^{\circ} \mathrm{C}$, whereas the other samples exhibited one endothermic peak at $70^{\circ} \mathrm{C}$. The low-temperature peak was related with elimination of the externally adsorbed water, whereas the high-temperature peak was due to desorption of the loosely bound zeolite water. The heats of dehydration values calculated from the DSC peak areas were in agreement with the values in the literature. The heats of dehydration decreased with the surface coverage for $\mathrm{NZ}$ and $\mathrm{H}-\mathrm{NZ}$, whereas it was almost independent of the surface coverage for $\mathrm{NH}_{4}-\mathrm{NZ}-15 \mathrm{~h}$. The decrease in the dehydration heat with the surface coverage was explained by tighter retention of water molecules by the cations at low surface coverages.

The changes in the state of different water molecules adsorbed in the zeolite during dehydration under vacuum were followed using DRIFTS. The heat of desorption values calculated based on the changes in the intensities of bands in DRIFT spectra with temperature allowed identification of different types of water molecules adsorbed in the zeolite. From the changes in the relative intensities of the bands associated with water as a function of temperature during the in situ dehydration, it was revealed that removal of the isolated $\mathrm{OH}$ groups requires higher heat compared to that for removal of the hydrogen-bonded $\mathrm{OH}$ groups. Because adsorption and desorption of water vapor in clinoptilolite are reversible processes, the heat absorbed during desorption would be released when water vapor was adsorbed in the samples. Thus, desorption with cheap and renewable energy sources such as solar energy and utilization of heat of adsorption in required places are possible with the zeolitic tuff. Around $900 \mathrm{~J} / \mathrm{g}$ zeolite heat will be released to the surrounding by saturation of the dehydrated tuff with water vapor.

\section{ACKNOWLEDGMENT}

This study was financially supported by the State Planning Organization (project number: 98K122130). The authors thank Dr. A. Allahverdiev for his contribution to experimental work.

\section{REFERENCES}

1. Mumpton, F. Clinoptilolite redefined. American Mineralogist 1960, 45, 351-369.

2. Knowlton, G.D.; White, T.R.; McKague, H.L. Thermal study of types of water associated with clinoptilolite. Clays and Clay Minerals 1981, 29, 403-411.

3. Esenli, F.; Kumbasar, I. Thermal behaviour of heulandites and clinoptilolites of Western Anatolia. Studies in Surface Science and Catalysis 1994, 84, 645-651.
4. Tsitsishvilli, G.V.; Andronikashvilli, T.G.; Filizova, L.D.; Kirov, G.N. Natural Zeolites; Ellis Horwood: New York, 1992.

5. Shepard, A.O.; Starkey, H.C. The effects of exchanged cations on the thermal behavior of heulandite and clinoptilolite. In Papers and Proceedings of the Fourth General Meeting, Mineralogical Society of India, New Delhi, India, December 15-22, 1964; 155-158.

6. Carey, J.W.; Bish, D.L. Calorimetric measurement of the enthalpy of hydration of clinoptilolite. Clays and Clay Minerals 1997, 45, 826-833.

7. Bish, D.L. Thermal behaviour of natural zeolite. In Occurrence, Properties, and Utilization of Natural Zeolites; Ming, D.W.; Mumpton, F.A., Eds.; Brockport: New York, 1995; pp. 259-269.

8. Van Reenwiijk, L.P. The thermal dehydration of natural zeolites. Mededelingen Landbouwhogeschool Wageningen 1974, 74, 1-88.

9. Breger, I.A.; Chandler, J.C.; Zubovic, P. An infrared study of water in heulandite and clinoptilolite. American Mineralogist 1970, 55, 825-840.

10. Armbruster, T.; Gunter, M.E. Stepwise dehydration of heulanditeclinoptilolite from Succor Creek, Oregon, U.S.A.: A single-crystal X-ray study at $100 \mathrm{~K}$. American Mineralogist 1991, 76, 1872-1883.

11. Kasture, M.W.; Joshi, P.N.; Soni, H.S.; Joshi, V.V.; Choudhari, A.L.; Shiralkar, V.P. Sorption properties of the natural, K, and partially deammoniated $\left(\mathrm{H} / \mathrm{NH}_{4}\right)$ forms of clinoptilolite. Adsorption Science and Technology 1998, 16, 135-151.

12. White, D.A.; Bussey, R.L. Water sorption properties of modified clinoptilolite. Separation and Purification Technology 1997, 11, 137-141.

13. Rege, S.U.; Yang, R.T. A novel FTIR method for studying mixed gas adsorption at low concentrations: $\mathrm{H}_{2} \mathrm{O}$ and $\mathrm{CO}_{2}$ on $\mathrm{NaX}$ zeolite and $\gamma$-alumina. Chemical Engineering Science 2001, 56, 3781-3796.

14. Osorio-Revilla, G.; Gallardo-Velázquez, T.; López-Cortés, S.; Arellano-Cárdenas, S. Immersion drying of wheat using Al-PILC, zeolite, clay, and sand as particulate media. Drying Technology 2006, 24, 1033-1038.

15. Djaeni, M.; Bartels, P.V.; Sanders, J.P.M.; van Straten, G.; van Boxtel, A.J.B. Process integration for food drying with air dehumidified by zeolites. Drying Technology 2007, 25, 225-239.

16. Djaeni, M.; Bartels, P.V.; Sanders, J.P.M.; van Straten, G.; van Boxtel, A.J.B. Multistage zeolite drying for energy-efficient drying. Drying Technology 2007, 25, 1053-1067.

17. Djaeni, M.; Bartels, P.V.; van Asselt, C.J.; Sanders, J.P.M.; van Straten, G.; van Boxtel, A.J.B. Assessment of a two-stage zeolite dryer for energy-efficient drying. Drying Technology 2009, 27, 1205-1216.

18. Djaeni, M.; van Straten, G.; Bartels, P.V.; Sanders, J.P.M.; van Boxtel, A.J.B. Energy efficiency of multi-stage adsorption drying for low-temperature drying. Drying Technology 2009, 27, 555-564.

19. Ülkü, S.; Balköse, D.; Baltacıoğlu, H.; Özkan, F.; Yıldırım, A. Natural zeolites in air drying. Drying Technology 1992, 10, 475-490.

20. Ülkü, S.; Çakıcıoğlu, F. Energy recovery in drying applications. Renewable Energy 1991, 1, 695-698.

21. Ülkü, S. Adsorption heat pumps. Journal of Heat Recovery Systems 1986, 6, 277-284.

22. Tihmınlığlu, F.; Ülkü, S. Use of clinoptilolite in ethanol dehydration. Separation Science and Technology 1996, 31, 2855-2865.

23. Çakıcıoğlu-Özkan, F.; Ülkü, S. The effect of $\mathrm{HCl}$ treatment on water vapor adsorption characteristics of clinoptilolite rich natural zeolite. Microporous and Mesoporous Materials 2005, 77, 47-53.

24. Çakıcıoğlu-Özkan, F.; Ülkü, S. Diffusion mechanism of water vapor in a zeolitic tuff rich in clinoptilolite. Journal of Thermal Analysis and Calorimetry 2008, 94, 699-702.

25. Ülkü, S. Natural zeolites in energy storage and heat pumps. Studies in Surface Science and Catalysis 1986, 28, 1047-1054.

26. Ülkü, S.; Balköse, D.; Alp, B. Dynamic heat of adsorption of water vapor on zeolitic tuff and zeolite $4 \mathrm{~A}$ by flow microcalorimetry. Oxidation Communications 2006, 29, 204-215.

27. Alver, B.E.; Sakızcı, M.; Yörükoğulları, E. Investigation of clinoptilolite rich natural zeolites from Turkey: A combined XRF, TG/DTG, 
DTA and DSC study. Journal of Thermal Analysis and Calorimetry 2010, 100, 19-26.

28. Bertsch, L.; Habgood, H.W. An infrared spectroscopic study of the adsorption of water and carbon dioxide by Linde molecular sieve $\mathrm{X}^{1}$. Journal of Physical Chemistry 1963, 67, 1621-1628.

29. Beta, I.A.; Böhlig, H.; Hunger, B. Investigation of the non-isothermal water desorption on alkali-metal cation-exchanged X-type zeolites: A temperature-programmed diffuse reflection infrared Fourier transform spectroscopic (TP-DRIFTS) study. Thermochimica Acta 2000, $361,61-68$.

30. Sani, A.; Vezzalini, G.; Ciambelli, P.; Rapacciuolo, M.T. Crystal structure of hydrated and partially $\mathrm{NH}_{4}$-exchanged heulandite. Microporous and Mesoporous Materials 1999, 31, 263-270.

31. Likhacheva, A. Yu.; Veniaminov, S.A.; Paukshtis, E.A. Thermal decomposition of $\mathrm{NH}_{4}$-analcime. Physics and Chemistry of Minerals 2004, 31, 306-312.

32. Zecchina, A.; Marchese, L.; Bordiga, S.; Paze, C.; Gianotti, E. Vibrational spectroscopy of $\mathrm{NH}_{4}^{+}$ions in zeolitic materials: An IR study. Journal of Physical Chemistry B 1997, 101, 1012810135 .
33. Stumm, W.; Morgan, J.J. Aquatic Chemistry: Chemical Equilibria and Rates in Natural Waters, 3rd Ed.; Wiley: New York, 1996.

34. Breck, D.W. Zeolite Molecular Sieves; Wiley: New York, 1974.

35. Akpolat, O.; Gündüz, G.; Özkan, F.; Beşün, N. Isomerization of $\alpha$-pinene over calcined natural zeolites. Applied Catalysis A: General 2004, 265, 11-22.

36. Tomazović, B.; Ćeranić, T.; Sijarić, G. The properties of the $\mathrm{NH}_{4}$-clinoptilolite. Part 1. Zeolites 1996, 16, 301-308.

37. Likhacheva, A. Yu.; Paukshtis, E.A.; Seryotkin, Yu. V.; Shulgenko, S.G. IR spectroscopic characterization of $\mathrm{NH}_{4}$-analcime. Physics and Chemistry of Minerals 2002, 29, 617-623.

38. Korkuna, O.; Leboda, R.; Skubiszewska-Zięba, J.; Vrublevska, T.; Gun'ko, V.M.; Ryczkowski, J. Structural and physicochemical properties of natural zeolites: Clinoptilolite and mordenite. Microporous and Mesoporous Materials 2006, 87, 243-254.

39. Crupi, V.; Longo, F.; Majolino, D.; Venuti, V. Vibrational properties of water molecules adsorbed in different zeolitic frameworks. Journal of Physics: Condensed Matter 2006, 18, 3563-3580.

40. Merkle, A.B.; Slaughter, M. Determination and refinement of the structure of heulandite. American Mineralogist 1968, 53, 1120-1138. 